\title{
RELEVANCE ANALYSIS OF MEASUREMENT MECHANICAL QUANTITIES IN THE COMPOSITION OF THE NETWORK "INTERNET OF THINGS" AND SYSTEMS OF PROFESSIONAL COOPERATION DURING METROLOGICAL STUDIES
}

\author{
Kvasnikov Volodymyr ${ }^{1}$ \\ Dudnik Andriy ${ }^{2}$ \\ Bondarenko Yuri ${ }^{3}$
}

DOI: http://dx.doi.org/10.30525/978-9934-571-26-8_8

Abstract. In our time, the need for separate use of measuring devices has significantly decreased.

This trend is characterized by two major changes in the world of electronic devices:

1. In modern devices, sensors have ceased to be independent systems or separate devices and are part of them (in their everyday life they are tablets and smartphones, and in the production they are sensory measuring networks).

2. Measurement systems themselves have ceased to be of interest. They are an integral part of the system, which also includes technologies for processing, measuring, storing and forecasting measurements.

An example of using such technologies is "Internet of Things", which can be considered as one of the IT-technologies that improve professional interaction, due to the shared use of this or that group of people

The research of information-measuring systems, including the research of the technologies of modeling, control and interaction of computerized systems of measuring mechanical quantities, is devoted to the work of modern scientists such as Kvasnikov V., Ornadsky D., Osmolovsky A., as well as works by Geyer D., Irwin J., Liery J., Roshan P., Stollings V., Harley D. et al.

\footnotetext{
${ }^{1}$ Doctor of Technical Sciences, Professor,

Head of the Department of Computerized Electrical Systems and Technologies,

National Aviation University, Ukraine

${ }^{2}$ Candidate of Technical Sciences, Associate Professor,

Associate Professor of the Department of Network and Internet Technologies,

Kyiv National University T. Shevchenko, Ukraine

${ }^{3}$ Postgraduate Student of the Department of Computer Multimedia Technologies, National Aviation University, Ukraine
} 
The subject of the study is the measuring sensor network "Internet of Things", as a kind of informational measuring system that is being solved as a system of professional interaction.

Research methods are the systematic method of analytical research, computer simulation, simulation modeling.

The purpose of the research is to analyze the problem of modern information measuring systems of mechanical quantities, to harmonize the basic concepts and terms, to analyze the concept of deployment of the sensory network "Internet of Things", to develop a basic simulation model of sensory measuring network of mechanical quantities as a means of professional interaction.

The article will analyze the problem of modern information measuring systems of mechanical quantities, will agree on the basic concepts and terms, will analyze the concept of deployment of the sensor network "Internet of Things", will develop a basic simulation model of sensory measuring network of mechanical quantities as a means of professional interaction.

\section{Introduction}

Today there is a decisive transition from individual measuring instruments to intelligent measurement systems of the future generation. In such systems can simultaneously provide coordinate services, weather forecast, and calorie measurement (based on what distance people overcame and at what speed).

Over time, cloud service access for historical data analysis, processing, and creation of metrics has also been added for further research (for example, Microsoft Azure Cloud Services).

Among this diversity of services one important problem is highlighted: the need for the rapid implementation of a measuring system, which will include both a monitoring system, an information flow management system, and a system that will be responsible for collecting and processing data for them in a professional interaction (shared use for better coordination of actions).

A good solution for such different requirements is the computerized measurement system. They consist of geographically distributed autonomous devices and their intelligent sensors related to them: temperature, sound, vibration, time positioning, etc., they can freely compete with existing measurement systems, and also serve as an addition to any existing measurement system with a professional interactions. 


\section{The role of professional interaction}

The category of interaction is one of the general categories of knowledge and inextricably linked with such basic categories as motion, space, time, structure; reflects the processes of the actions of various objects on each other, their mutual conditionality, state change, interconnection and is defined as the process of integration activities of subjects.

The essence of interaction consists in the continuity of direct and reciprocal action, the organic combination of changes of actors that affect each other. It is a holistic, internally differentiated, self-evolving system. This understanding of interaction involves a mutual change in managers and managed actions, convinces in the need to consider changes in interacting subjects and the process of interaction as a change in its states.

Theories of interpersonal interaction represent it as a material process accompanied by the transfer of matter, movement and information: as a collaboration, a joint activity (B. Lomov, O. Leontiev, A. Zhuravlev), empathy (J. Homans, E. Hoffman, J. Schepansky ), communication (G. Andreev).

In the structure of interaction distinguish transactions (E. Bern), interactions (J. Mead, R. Blummer), influences (A. Zhuravlev), contact, relations, actions (Ya Shchepansky); emotions and problems (R. Bails), mutual interest (G. Andreev). V. Semikin states that in the structure of interaction, different authors singled out the same components, calling them differently: practical (V. Myasishchev), behavioral (Ya. Kolominsky), regulatory (B. Lomov) - includes results of activity and deeds, facial expressions, gesticulation, pantomime and speech; the second is affective, which includes what is related to the emotional state and experiences of the individual; the third is Gnostic (V. Myasishchev), cognitive (Y. Kolominsky), informational (B. Lomov) characterizing the activity of the person receiving and processing information.

The variety of approaches to the definition and structure of interaction leads to the conclusion that interaction as a socio-psychological category is an integrative factor, which unites the parts into a holistic process of direct or indirect interaction of objects (entities) that generates their mutual conditionality and connection.

The interaction involves not only two individuals, but also some groups, groups as a whole. In categories that characterize the interaction in the general plan and reflect the peculiarities of the professional activity of a 
specialist, in particular a specialist in commercial activity, we consider it necessary to include the purpose, subject, methods, feedback.

The purpose of interaction provides purposefulness (in contrast to spontaneity) of joint activity, communication and empathy of subjects. The purpose of the interaction is to represent the intended result of the activity, which is in the general interest and contributes to the realization of the needs of each of its participants (C. Golovin); ensures controllability of the mutual actions of the subjects. Researchers G. Andreyev, A. Zhuravlev, O. Leontiev to the purpose of interaction include optimization of relations, intensification, stimulation, activation, management, development, formation, prevention, evaluation, information.

The object of interaction forms a "field", "space", in relation to which there are mutual actions of subjects. As an object of interaction act, according to R. Bayles, emotions and problems. A. Zhuravlev calls the interaction of subjects subject-oriented, emphasizing the objectivity of mutual actions. The subject of interaction are ties, relationships, co-decision, mutual interest, the commonality of emotional experiences, the formulation and solution of problems (G. Andreev, A. Harasch).

Methods of interaction are represented by methods, technologies of organization of communications; manifested as interpersonal relationships, interpersonal relationships; characterize awareness, mutual understanding, interrelation of actions of subjects in relation to the subject of interaction.

Feedback as an attribute of interaction serves as a reciprocal reaction to action, provides feedback to the action of the subject and characterizes the subjectivity of the other side of the interaction. O. Solovieva calls it a mirror image, a reaction to influence, understanding, mechanism, ensuring the existence of interaction [12, p. 103]. The feedback reveals the changes of the interacting actors, the reaction to influences, signals the state of the object of interaction, actualizes the way of interaction, approximates or removes from the purpose of interaction (Y. Harutyunyan, V. Konets'ka, L. Petrovskaya). The presence of feedback provides manageability, target orientation, reciprocity.

Feedback, according to L. Petrushenko, can be a visual observation, audio message, an electrical signal, have the form of messages, reports, written reports [11, p. 67]. L. Petrushenko points out that the cybernetic notion of feedback is not limited to the concept of reverse effect or physical feedback channel. For cybernetic systems, not all feedback is important, 
but above all, the one that regulates the reciprocal action by passing the information necessary for it to the available changes of all aspects of the interaction.

Consequently, interaction is a process of purposeful, objective, organized guided and variable-purpose methods and feedback that promotes interrelated and interdependent change of subjects. Such an understanding of the interaction corresponds to the situation of professional activity of specialists in commercial activity, since it contains an indication of the need to implement both the subject-object and the subject-subject relations.

\section{Heredity of terms and concepts}

Measuring information system (MIS) - a set of measuring instruments, control means, diagnostics and other technical means combined for the creation of signals of measurement and other types of information [12, p. 110] in order to provide it to the consumer (including ASC) in the right form.

Information-measurement system - a set of functionally combined measurement, computing and other auxiliary technical means for obtaining measurement information, its transformation, processing in order to provide the consumer (including input to the Automatic Control System) in the required form or automatic implementation of the logical functions of control, diagnostics, identification.

Internet of Things (IoT) is a network concept consisting of interconnected physical devices that have built-in sensors, as well as software that allows the transmission and exchange of data between the physical world and computer systems, using standard communication protocols. In addition to sensors, the network may have actuators built into physical objects and interconnected via wired or wireless networks. These interconnected devices have the ability to read and execute, the programming function and identification, and also eliminate the need for human involvement through the use of intelligent interfaces.

Method of measurement - a set of methods for using measuring instruments and measurement principles to create measurement information.

Based on these definitions, we can conclude that the Internet of Things network is one of the types of information measuring systems. Also, this network can be used as a measurement method based on certain rules of the interaction of measuring devices and devices that are controlled. In particular, this also applies to the mechanical quantities corresponding to the 
Relevance analysis of measurement mechanical quantities in the...

passport of the specialty "Instruments and methods of measuring mechanical quantities."

\section{Concept of "Internet of Things" network}

The basic concept of the Internet of things is the ability to connect all sorts of objects (things) that a person can use in everyday life, for example, a refrigerator, air conditioner, a car, a bike and even sneakers. All these objects (things) must be equipped with built-in sensors or sensors, which have the ability to process the information coming from the environment, exchange it and perform various actions depending on the information received. An example of implementing such a concept is the "smart home" or "smart farm" system. This system analyzes the data of the environment and, depending on the indicators, regulates the temperature in the room. In the winter, the intensity of heating is regulated, and in the case of hot weather, the house has mechanisms for opening and closing windows, which makes the house airing, and all this happens without human intervention.

Several technologies are needed to connect everyday things to the network.

- To identify each object you need a simple, compact technology. Only if there is a unique identification system can collect and accumulate information about a particular subject. Such a functionality can be provided with RFID chips (Radio-Frequency Identification). They are able to transmit information to readers without their own source of current. Each chip has an individual number. As an alternative to this technology, QR codes can be used to identify objects. To determine the exact location of the thing suitable GPS technology, which is effectively used today in smartphones and navigators.

- Objects should be equipped with sensors to monitor changes in the state of an element or the environment.

- An integrated computer (such as Raspberry Pi, Intel Edison) should be used to process and accumulate sensor data.

- Wireless technology (Wi-Fi, Bluetooth, ZigBee, 6LoWPAN) can be used to share information between devices.

Internet integration implies that devices will use the IP address as a unique identifier. However, due to limited IPv4 address space (which allows 4.3 billion unique addresses), IPs will have to use IPv6, which provides 
unique network layer addresses of at least 300 million devices per inhabitant of the Earth. Objects in the IP will be not only devices with sensory capabilities, but also devices that perform actions (for example, bulbs or locks that are controlled via the Internet). To a large extent, the future of the Internet of things will not be possible without the support of IPv6, hence the global introduction of IPv6 in the coming years will be crucial for the successful development of IP in the future.

For wireless data transmission, the following characteristics, such as efficiency, fault tolerance, adaptability, the possibility of self-organization, play a particularly important role in the construction of the Internet of things. The main interest in this sense is IEEE 802.15.4, an access control for the organization of energy efficient personal networks, and is the basis for protocols such as ZigBee, WiFi, Bluetoot, 6LoWPAN.

ZigBee is a communication technology based on the IEEE 802.15.4 protocol for the implementation of low-speed wireless private networks. ZigBee has features such as low power consumption, low data rates, low cost and high bandwidth. ZigBee is currently used mainly for transmitting information between different electronic equipment items that are within short distances and data rates are not very high. This is mainly peripherals (mouse, keyboard) and consumer electronics (TV, DVD), as well as industrial control devices (monitors, sensors and automation tools).

Many publications under the IEEE 802.15.4 standard understand ZigBee technology and vice versa under ZigBee, the IEEE 802.15.4 standard. However, this is not the case. The IEEE 802.15.4 standard defines the interaction of only two lower levels of the interaction model (Figure 1) [1, p. 22]:

- Physical level (PHY) level of access control to the radio channel for three unlicensed frequency bands: $2.4 \mathrm{GHz}, 868 \mathrm{MHz}$ and $915 \mathrm{MHz}$.

- The MAC is responsible for controlling access to the radio channel using the Carrier Sense Multi Access with Collision Avoidance (CSMA/ CA) method, as well as for controlling the connection and disconnection from the data transmission network and providing security Transmitted information by symmetric key AES-128. This protocol will be used for further research.

Wi-Fi is a local wireless technology that uses $2.4 \mathrm{GHz}$ ultra-high frequency or $5 \mathrm{GHz}$ super-high-frequency radio waves. This technology is very suitable for transmitting large volumes of data over a wireless network between devices, but it also requires a lot of power to work and has a low 
Relevance analysis of measurement mechanical quantities in the...

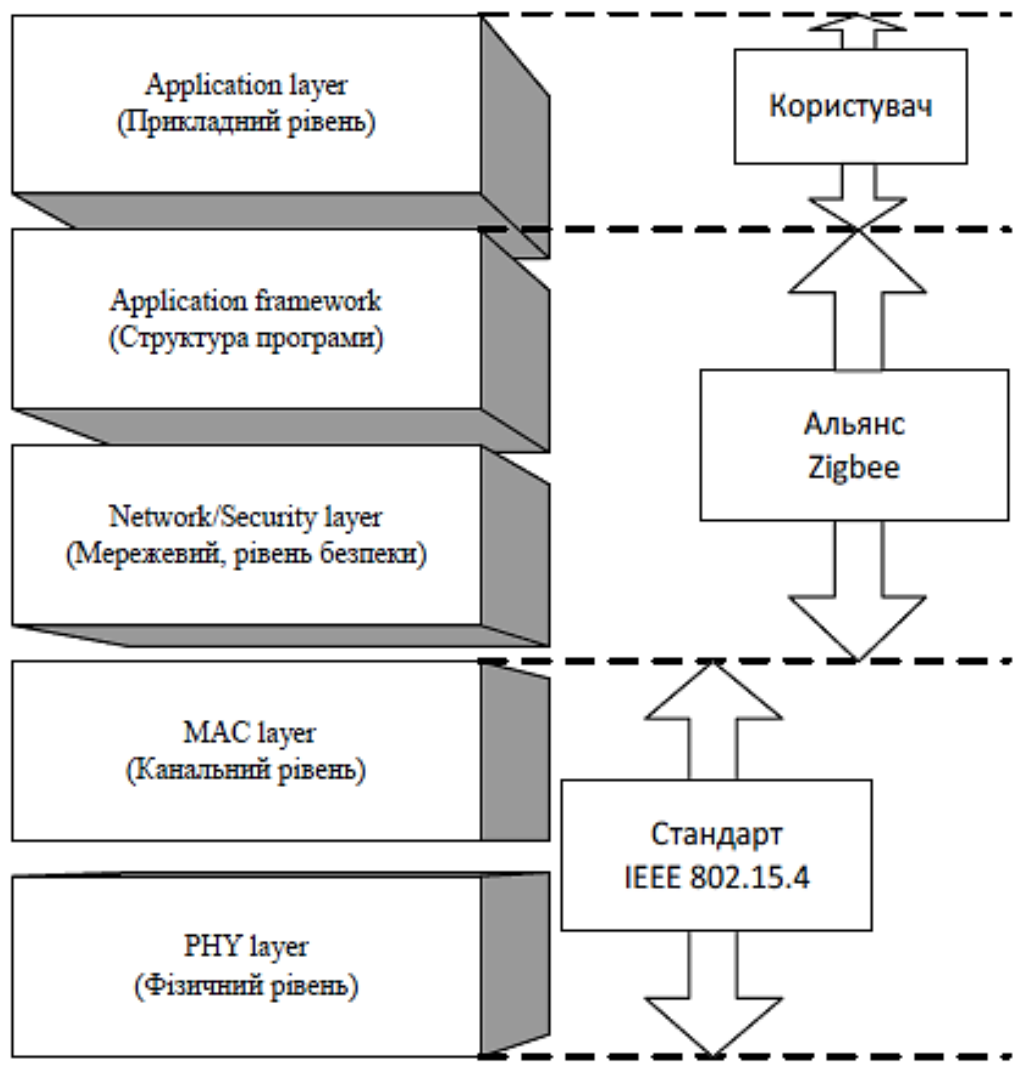

Fig. 1. ZigBee protocol decomposition model [3, p. 22]

level of data bandwidth. When using this technology, it will be necessary to replace the batteries on all devices on a regular basis.

Bluetooth is a wireless technology used to transfer data to personal networks. It transmits data over the band from 2.4 to $2.485 \mathrm{GHz}$ and operates at shorter distances than Wi-Fi. You can synchronize a couple of devices, such as phones, headphones, speakers, computers, and more. With the development of Bluetooth v4.0, it was possible to implement the low power function and increased the range of up to several tens of meters.

Among the leading technologies, the PLC solution, the technology for building data transmission networks over power lines, plays an important 
role in distributing the Internet of things, since many applications have access to power grids (for example, vending machines, ATMs, intelligent meters, lighting controllers are originally connected to the power supply network). 6LoWPAN, which implements an IPv6 layer over both IEEE 802.15.4 and above the PLC, being an open protocol, standardized by the IETF, is seen as particularly important for the development of the Internet of Things.

The Internet of things can cause tremendous changes in everyday life, giving ordinary users a whole new level of comfort. But if the elements of such a system are not adequately protected from unauthorized interference, they will use a reliable cryptographic algorithm instead of the benefit, by giving cybercriminals a loophole to undermine information security. Because things with built-in computers store a lot of information about their owner, including the exact location of their site, access to such information can help intruders commit a crime. The lack of standards for the protection of such autonomous networks is currently slowing down the implementation of the Internet of things in everyday life.

\section{Actuality of sensory networks}

The interest in automation networks grows each year due to their low cost and relative simplicity of installation. One of the most promising areas for using these WSN networks is the automation of buildings and premises [9, p. 195], for example, automated systems for temperature and illumination control. The number of incoming sensors (wired sensors) for climate control at someone and the intelligent house (Intelligent House) can be significant, which inevitably leads to high installation and installation costs, and even in some cases, even before the building is reconstructed for laying cable systems Therefore, an economical and efficient alternative to the CAN, BACnet, LonTalk, Ethernet, and TokenBus protocols is a modern wireless sensor network (WSN) in the "Internet of Things".

Sensory patrons play an increasingly important role in the automation of industrial buildings, buildings and facilities (Smart Ambiences), in the monitoring of areas used in health care, agriculture, forestry and animal husbandry, ecology, ornithology, aircraft engineering, and to the gate. But the list of applications, of course, is far from complete. The WSN wireless sensory networks with Wi-Fi and WiMAX networks, which address office communication tasks (Fig. 1), are integrated into the system. 


\section{Relevance analysis of measurement mechanical quantities in the...}

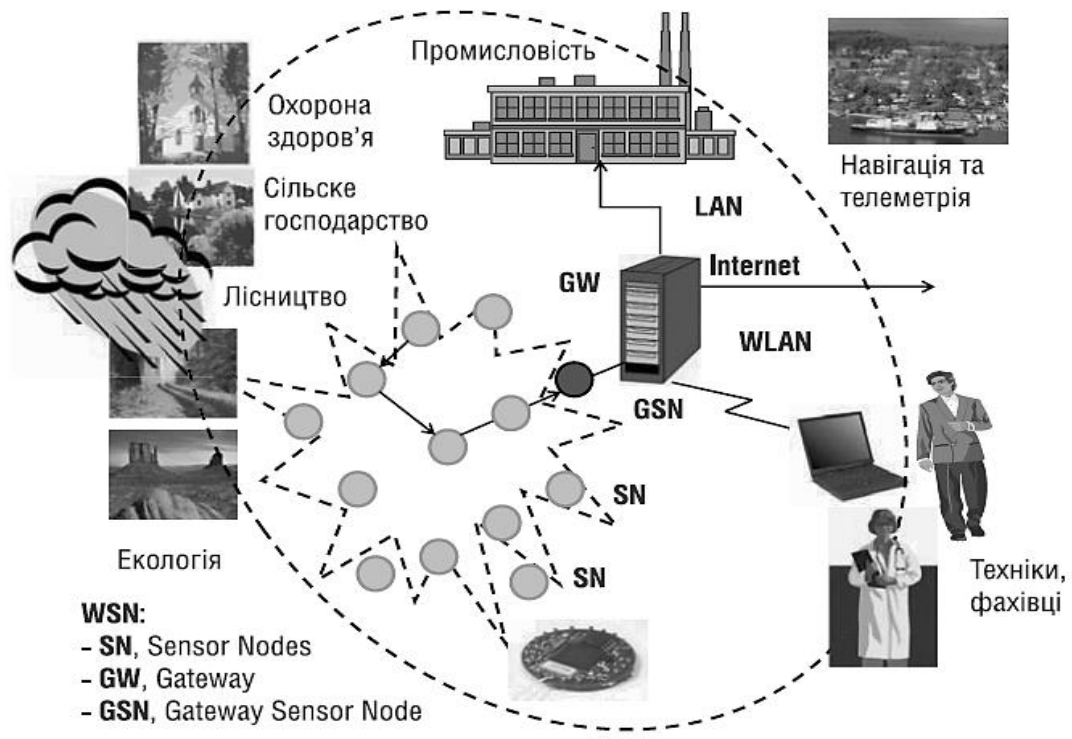

Fig. 2. Areas of application of sensory pawns WSN [9, p. 196]

On the whole, the WSN's coasts are composed of spatially-allocated autonomous units (SN, Sensor Nodes) that communicate with the purpose of joint monitoring of physical parameters or ambient conditions such as air temperature, sound, vibration, and pressure, movement of parts during structural assembly or diffusion of pollutants into the air. The model and parameters without a proximity sensor are shown in Fig. 2.

In most pockets, microcontrollers installed in nodes are implemented in 8-bit Harvard architecture with an average RAM (128-Kb) and $64 \mathrm{~kb}$ data. For the most part, the transmission frequency is in the range of $\mathrm{F}=315 \ldots 916 \mathrm{MHz}$ (Mica2, Mica2Dot) or $\mathrm{F}=2.4 \mathrm{GHz}$ (ZigBee IEEE 802.15 .4 , Imote). The data transfer speed of DR is usually small and ranges from $38 \mathrm{kBits} / \mathrm{s}$ to $0.7 \mathrm{MB} / \mathrm{s}$. The radius of the sensor is in the range of 30 to $150 \mathrm{~m}$. The energy consumption is determined by the sensor operation phase and is up to $1,000 \mathrm{~mW}$ for data transmission and reception, $100 \mathrm{~mW}$ for Idle Mode and up to $0.05 \mathrm{~mW}$ for partial mode Sleep Mode. The average transmit power is PTx $=4-10 \mathrm{dBm}$. To provide Real Time Requirements in the WSN automation outings, only short mes- 


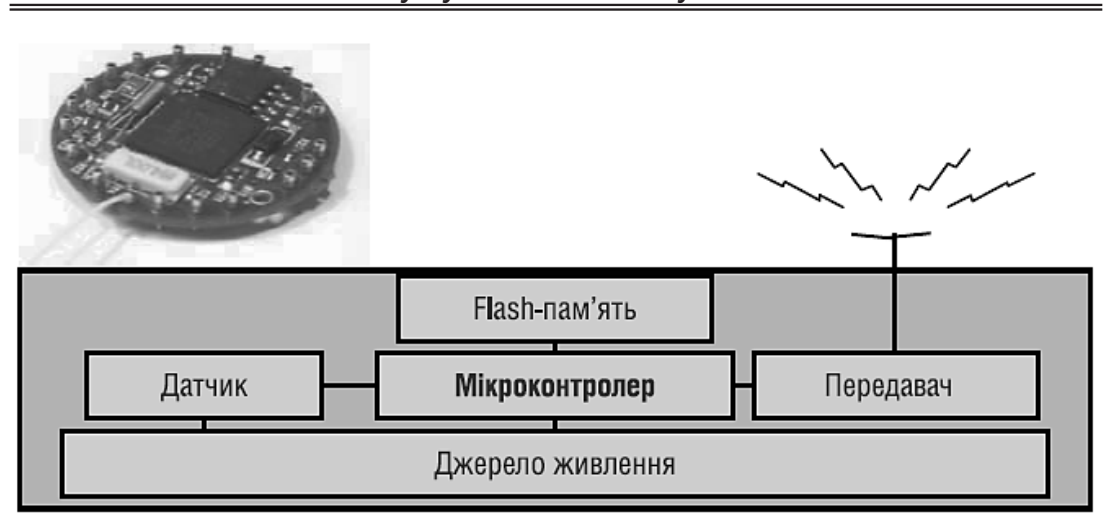

Архітектура мікроконтролера розрядністю 8 біт: Приклад CPU: Intel StrongARM

- Оперативна пам'ять програм - 128 KB;

- Оперативна пам'ять даних RAM - 64 KB;

- Flash-пам'ять - $1 \mathrm{MB}$;

- Частотний діапазон:

- швидкість передавання: $D R=38 \mathrm{k} 6 \mathrm{iT} / \mathrm{c}-0,7 \mathrm{M \sigma iT} / \mathrm{c}$;

- відстань: $D=30-150 \mathrm{~m}$;

- $F=315-916$ МГц для Мica 2, Mica2Dot;

- живлення: максимум 1000 мBт;

- потужність передавання: $P T X=4-10$ дБм;

$-F=2,4$ ГГц для ZigBee IEEE 802.15.4, Imote

- короткі повідомлення: $T L=100$ біт/1 мс;

- Операційна система: Tiny OS

Fig. 3. Model and parameters of the wireless sensor $[9$, p. 200]

sages that are called telegrams are allowed (TL $\sim 100$ bits) with relatively small headers (overhead, $\mathrm{OH}$ ).

In sensory networks, sensors can be the most diverse; they are connected via digital and analog connectors. Most often other sensors use temperature, pressure, humidity, illumination, vibration, less often - magnetoelectric, chemical (for example, measuring the content of $\mathrm{CO}, \mathrm{CO} 2$ ), sound and some others [3, p. 10]. The set of sensors depends on the functions performed by the wireless sensor networks. Node power is provided by a small battery and used only for collecting, processing and transmitting sensory data. The appearance of nodes manufactured by different manufacturers is shown in Figure 4.

\section{Improved accuracy of measurements}

When solving many practical problems arising in instrument making, as well as in conducting research, there is a shortage of information due to the nature of the measurement of the function of the state and other factors. 

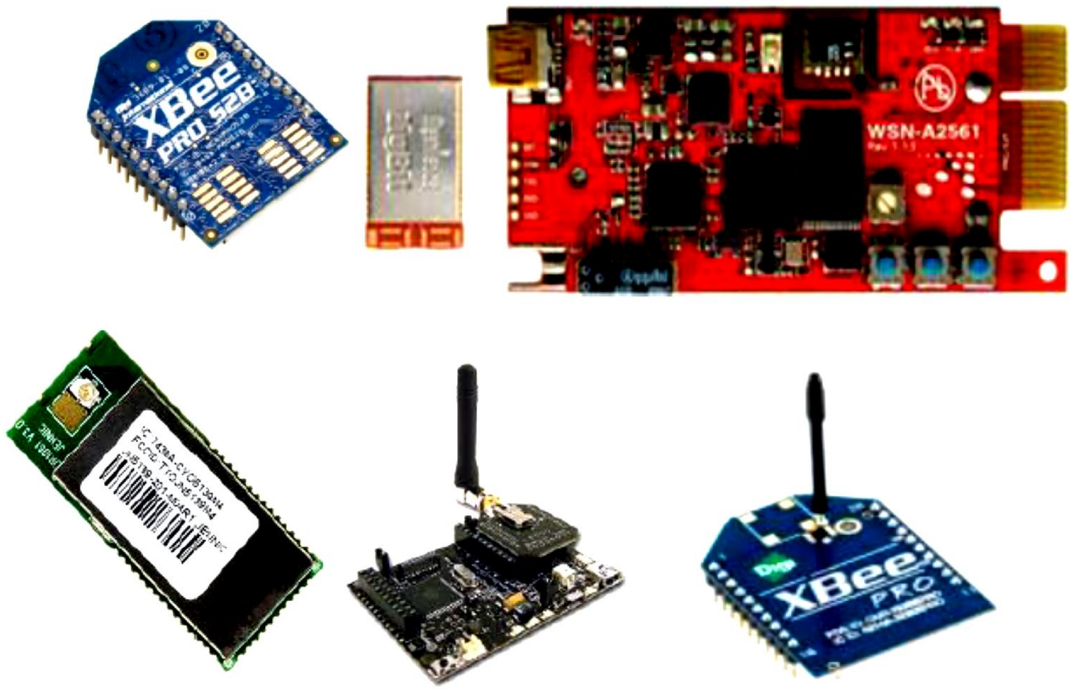

Fig. 4. ZigBee sensor network devices

The specified deficit is replenished by solving the problems of controlling distributed systems that are part of the Internet of Things network such as mathematical modeling, estimating the state and parameters of stochastic processes, minimizing the number of measuring points and optimizing their location in the spatial domain.

Formulation of the problem. Consider the case of measuring (estimating) the vector information parameter under the influence of the additive interference with the non-Gaussian probability distribution density in the "Internet of Things" sensory network based on ZigBee.

The random process selection $X_{h}=X\left(t_{h}\right), h=1, \ldots, H$, is a mixture of the useful signal $S\left(\lambda, t_{h}\right)$, that carries information about the measurement information parameters $\lambda=\left\{\lambda_{1}, \ldots, \lambda_{\mathrm{m}}\right\}$, and additive generally non-Gaussian noise $n_{h}[8$, p. 1]

$$
X\left(i_{h}\right)=S\left(\lambda, t_{h}\right)+n_{h} .
$$

We believe that the results of measurement of mechanical quantities are functions of sufficient statistics and have asymptotic properties of sufficiency, instability and normality, as well as the regularity conditions are 
fulfilled. We believe that additive interference and measurement parameters are independent.

The task of determining the optimal filtering of the random process of measuring mechanical quantities is to convert a signal $\xi$ to the target as the most accurate reproducing $S$. The distribution density $p(x / \lambda)$ depends on the vector parameter $\lambda=\left\{\lambda_{1}, \ldots, \lambda_{s}\right\}, p \geq 2$. To obtain a timetable in a power polynomial relative $x$

$$
\ln p_{s}(x / \lambda)=\int_{a}^{\lambda} \sum_{i=1}^{s} k_{i}(t)\left[x^{i}-m_{i}(t)\right] d t+c_{s}(x)
$$

where $c_{s}(x)$ - he function that does not depend on $\lambda$, and for the convergence in $x$ sequence $\left\{\ln p_{s}(x / \lambda)\right\}$ to the logarithm of the distribution density $\ln p(x / \lambda)$ at $s \rightarrow \infty$ need to $k_{i}(\lambda)$ are determined from the solution of the system of linear algebraic equations [8, p. 3]

$$
\sum_{j=1}^{s} k_{j}(\lambda) F_{i j}(\lambda)=\frac{d}{d \lambda} m_{i}(\lambda), i=\overline{1, s},
$$

де $F_{i j}(\lambda)=m_{i+j}(\lambda)-m_{i}(\lambda) m_{j}(\lambda) i, j=\overline{1, s}, m_{i}(\lambda), m_{j}(\lambda)$ - moments. According to the schedule (1), to find the vector parameter, the approximation of the compatible density distribution of independent sample values will have the form

$$
p_{s n}(x / \lambda)=\exp \left\{\sum_{i=1}^{s} h_{m i}(\lambda) \cdot t_{i n}+h_{0}(\lambda)+c_{s}\left(x, \lambda / \lambda_{m}\right)\right\}
$$

where the notation is introduced:

$$
\begin{gathered}
h_{m i}(\lambda)=\int_{a}^{\lambda} k_{i m} d t, \\
h_{0}(\lambda)=n \int_{a}^{\lambda} \sum_{i=\lambda}^{s} k_{i}(t) b_{i}(t) d t, \\
t_{i n}=\sum_{r=1}^{n} c_{s}\left(x_{r}\right),
\end{gathered}
$$

But $c_{s}\left(x, \lambda / \lambda_{m}\right)$ - function independent of the composite vector parameter.

In accordance with the Cramer-Rao theorem, the variance of any unbiased estimation is determined by the inequality [1]

$$
G_{\lambda}^{2} \geq\left[-m\left\{d^{2} \ln W_{n}(\lambda) / d \lambda^{2}\right\}\right]^{-1},
$$


Where $W_{n}(\lambda)$ - function of plausibility.

We believe that the logarithm of the probability function (LFP) exists and has the form

$$
B_{n}=\ln W_{n}\left\{X_{h}-S\left(\lambda, t_{h}\right)\right\},
$$

Where $W_{n}\{*\}$ - There is an additive interference.

To evaluate the accuracy of the measurement of the vector information parameter, we shall consider, for example, the random vibrational processes that occur when the foundation is fluctuating in flexible production systems and frequency measurement $-\omega$, frequency derivative $-\omega^{\prime}$ and phase $-\varphi$ of the useful signal of the sensors

$$
S\left(\lambda, t_{h}\right)=U_{m h} \cos \left[\left(\omega+0,2 \omega^{\prime} t_{h}\right) t_{h}+\phi\right] .
$$

Let's represent a useful signal (2) $S\left(\lambda, t_{h}\right)$ in the form

$$
S\left(\lambda, t_{h}\right)=U_{m h} \cos \left(\lambda_{1}+\lambda_{2} t_{h}+\lambda_{3} t_{h}^{2}\right),
$$

де $\lambda_{1}=\varphi ; \lambda_{2}=\omega^{\prime} ; \lambda_{3}=\omega$.

For a measuring signal we define the derivatives:

$$
S_{\lambda i}^{\prime}\left(\lambda, t_{h}\right)=U_{m h} t_{h}^{i-1} \sin \left(\hat{\lambda}_{1}+\hat{\lambda}_{2} t_{h}+\hat{\lambda}_{3} t_{h}^{2}\right) i=1,2,3 .
$$

In estimating the information parameters for the maximum of the a posteriori density of probability distribution (ASSR), three equations are fulfilled:

$$
\left.\frac{d}{d \lambda_{1}} \ln W_{y}(\lambda)\right|_{\lambda_{1}=\lambda}=0 ;\left.\frac{d}{d \lambda_{2}} \ln W_{y}(\lambda)\right|_{\lambda_{2}=\hat{\lambda}}=0 ;\left.\frac{d}{d \lambda_{3}} \ln W_{y}(\lambda)\right|_{\lambda_{3}=\lambda}=0 .
$$

The Cramér-Rao lower bound on the variance of unbiased common parameters of useful signal $\lambda=\left\{\varphi, \omega, \omega^{\prime}\right\}$, may be written as $[4$, p. 2]:

$$
G_{\lambda i j}^{2} \geq\left|I_{i j}\right| / I \mid ; i, j=1,2,3
$$

where $\left|I_{i j}\right|$ - the algebraic complement of the element $I_{\mathrm{ij}} \mathrm{s}$ the algebraic complement of the element $\|I\| ;|I|$-determinant of the matrix.

\section{Conclusions}

Thus, in this paper an attempt was made to consider the combination of metrology, computer information systems and networks, as well as psychological theory of professional interaction, to solve common problems, in order to improve the automatic exchange of information about the state of the environment between end-user devices. In order for devices connected to the Internet of things, based on the information received, could carry out control actions that are useful to consumers. 
To this end, the role of professional interaction, as a system of communication between people, and its main components that can improve the Internet of Things network, was determined.

The choice of "Internet things" technology was substantiated and proved that this technology can be one of the types of information measuring systems and can be used as a method for measuring mechanical quantities.

The basic protocols that can be used in the Internet of Things network are analyzed and the ZigBee IEEE 802.15.4 protocol is chosen which is most suitable for constructing sensor networks and describes the model of its decomposition.

The main areas of application and structure of ZigBee IEEE 802.15.4 devices are considered.

The method of increasing the accuracy of measurements of mechanical quantities for a sensor network based on the ZigBee protocol is proposed.

\section{References:}

1. Institute of Electrical and Electronics Engineers (2003) IEEE Standard for Information Technology - telecommunications and Information Exchange between Systems - Local and Metropolitan Area Networks - Specific Requirements [IEEE Standard for Information Technology - telecommunications and Information Exchange between Systems - Local and Metropolitan Area Networks - Specific Requirements], New York: IEEE Press.

2. Kvasnikov V.P., Ganeva T.I. (2015) Method of measurement of stress in loaded structures [Method of measurement of stress in loaded structures]. Scientific and technical journal "Metallurgical and Mining Industry", vol. № 7, pp. 340-343.

3. Artyushenko V.M., Solenov V.I. (1997) Otsenka tochnosti izmereniya informatsionnogo parametra signala na fone additivnoy negaussovoy pomekhi [Estimation of the accuracy of measuring the information parameter of a signal against the background of additive non-Gaussian noise], Vestnik MGTU. Seriya Priborostroyeniye, vol. 4, pp. 9-14.

4. Kvasnikov V.P., Khaeyn T.M. (2013) Kontseptsiya povirky koordynatno-vymiryuval'nykh mashyn cherez Internet [Concept of verification of coordinate-measuring machines via the Internet], Metrolohiya ta prylady, vol. 6, pp. 48-53.

5. Kvasnikov V.P., Hanyeva T.I. (2015) Nova metodyka rozrakhunku datchyka deformatsiy [New method for calculating the deformation sensor]. Vymiryuval'na ta obchyslyuval'na tekhnika $v$ tekhnolohichnykh protsesakh, vol. 3, no. 52, pp. 169-173.

6. Kvasnikov V.P., Leshchenko YU.P. Rozrobka ta doslidzhennya intelektual'noyi systemy dlya analizu ymovirnisnykh kharakterystyk vypadkovykh protsesiv mekhanichnykh velychyn [Development and research of the intellectual system for the analysis of probabilistic characteristics of random processes of mechanical quantities]. Tekhnolohycheskyy audyt y rezervy proyzvodstva, vol. 5/3, no. 100-102. 
7. Kunchenko YU.P. (2002) Stokhasticheskiye polinomy, ikh svoystva i primeneniye dlya nakhozhdeniya otsenok parametrov [Stochastic polynomials, their properties and applications for finding estimates of parameters]. Cherkassy.: CHITI. (in Ukreine)

8. Luntovs'kyy A.O., Mel'nyk I.V. (2011) Osnovy proektuvannya bezprovodovykh komp'yuternykh merezh [Fundamentals of Designing Wireless Computer Networks]. Kyyiv: Universytet "Ukrayina". (in Ukreine)

9. Ornatskiy D.P., Kvasnikov V.P., Osmolovskiy A.I. (2014) Optimizatsiya analogovogo interfeysa informatsionno-izmeritel'nykh sistem dlya distantsionnykh izmereniy mekhanicheskikh velichin [ptimization of the analog interface of information-measuring systems for remote measurements of mechanical quantities]. Vostochno-Yevropeyskiy zhurnal peredovykh tekhnologiy, vol.4, no. 70, pp. 31-37.

10. Rogov Ye.I. (2004) Psikhologiya obshcheniya [Psychology of communication]. Moscow: Vlados. (in Russian)

11. Bilen'kyy YE. A. (2003) Sotsiolohiya: slovnyk terminiv i ponyat' [Sociology: dictionary of terms and concepts]. Zhytomyr : Volyn' : Ruta (in Ukraine)

12. Stukhlyak P.D. (2011) Teoriya informatsiyi (informatsiyno-vymiryuval'ni systemy, pokhybky, identyfikatsiya) [Theory of information (information-measuring systems, errors, identification)]. Kherson: Aylant (in Ukraine)

13. Shteynvol'f A.L. (1993) Raschety i imitatsiya negaussovykh sluchaynykh vibratsiy [Calculations and imitation of non-Gaussian random vibrations]. Kiyev: Naukova dumka (in Ukraine) 